\title{
OBTENÇÃO E CARACTERIZAÇÃO DE BLENDAS COLÁGENO-QUITOSANA
}

Edivan Tonhi*

Instituto de Química, Universidade Estadual de Campinas, CP 6154, 13083-970 Campinas - SP

Ana Maria de Guzzi Plepis

Departamento de Química e Física Molecular, Instituto de Química de São Carlos, Universidade de São Paulo, CP 780, 13560-970

São Carlos - SP

Recebido em 15/8/01; aceito em 19/2/02

\begin{abstract}
PREPARATION AND CHARACTERIZATION OF COLLAGEN-CHITOSAN BLENDS. Biodegradable polymer blends were obtained using collagen and chitosan. Membranes of collagen and chitosan in different proportions (3:1, 1:1 and 1:3) were prepared by mixing their acetate solutions ( $\mathrm{pH} 3.5$ ) at room temperature. The blends were characterized by differential scanning calorimetry (DSC), thermogravimetric analysis (TGA), Fourier Transform infrared (FTIR) spectroscopy, specific viscosity, water absorption and stress-strain assays. The results showed that chitosan did not interfere in the structural arrangement of the collagen triple helix and the properties of the blends can be controlled by varing the proportion of the collagen and the chitosan.
\end{abstract}

Keywords: blends; collagen; chitosan.

\section{INTRODUÇÃo}

O colágeno é uma proteína fibrosa presente na pele, tendões, ossos, dentes, vasos sangüíneos, intestinos e cartilagens, correspondendo a $30 \%$ da proteína total e a $6 \%$ em peso do corpo humano.

A quitosana é um copolímero constituído de $\beta$-(1-4)-2-amino-2deoxi-D-glicopiranose e $\beta$-(1-4)-2-acetamida-2-deoxi-D-glicopiranose, proveniente da reação de desacetilação da quitina, o segundo polissacarídeo mais abundante na natureza.

O colágeno e a quitosana têm sido bastante utilizados na medicina, odontologia e farmacologia como biomateriais, pois são polímeros biocompatíveis, atóxicos e biodegradáveis, além de possuírem inúmeras propriedades biológicas ${ }^{1-6}$.

As blendas poliméricas constituem-se na mistura de pelo menos dois polímeros ou copolímeros sem que haja qualquer reação química entre eles ${ }^{7}$. O interesse nesta área deve-se às crescentes aplicações práticas destes novos materiais e os principais estudos são voltados para a melhoria de suas propriedades físicas, físico-químicas e de processamento destes materiais, comparadas às propriedades dos polímeros puros ${ }^{8}$.

Muitas blendas formadas pela combinação de biopolímeros, têm grande importância na área de biomateriais, sendo que é possível juntar as propriedades individuais de cada material em um só, além da possibilidade de melhorar ou controlar as suas propriedades mecânicas e biológicas através da interação entre as suas estruturas químicas diferentes. Recentemente, membranas e hidrogéis provenientes da mistura de colágeno e quitosana foram investigados pelas suas aplicações potenciais no campo dos biomateriais ${ }^{9,10}$.

Já foi demostrado que as interações entre o colágeno e a quitosana dependem da organização estrutural do colágeno e da quantidade e distribuição de cargas ao longo das cadeias dos dois polímeros ${ }^{11}$. Estas propriedades estão diretamente relacionadas com o pH do meio, que é uma propriedade de fundamental importância para o estudo da interação entre eles em solução.

\footnotetext{
*e-mail: edivan@iqm.unicamp.br
}

Este trabalho teve por objetivos obter blendas colágeno-quitosana em diferentes proporções (3:1, 1:1 e 1:3) em pH 3,5, estudar a interação entre estes dois biopolímeros tanto na forma de membranas como em solução e avaliar suas propriedades físico-químicas.

\section{PARTE EXPERIMENTAL}

\section{Colágeno}

O colágeno foi extraído de serosa suína tratada com solução aquosa contendo dimetilsulfóxido (DMSO) $6 \%$ (v/v) e ácido acético pH 2,0 por $24 \mathrm{~h}^{12}$. Este tratamento foi repetido até que o $\mathrm{pH}$ da solução se estabilizasse em 2,0. O DMSO foi removido por lavagens com solução de ácido acético $0,55 \mathrm{~mol} \mathrm{~L}^{-1}(\mathrm{pH} \mathrm{3,5)}$ até $\mathrm{pH}$ constante. Após estabilização, a solução foi homogeneizada em um liquidificador. A concentração do gel foi $1,30 \%(\mathrm{~m} / \mathrm{m})$, determinado por liofilização.

As massas molares dos constituintes do colágeno foram determinadas por eletroforese em gel de poliacrilamida-SDS ${ }^{13}$, usando-se um gel de empacotamento de $5 \%$ e de resolução de $7 \%$, comparando-se com padrões conhecidos de albumina de soro bovino (BSA), ovoalbumina e gliceraldeído-3-fosfato-dehidrogenase. A razão das cadeias polipeptídicas $\alpha_{1}$ e $\alpha_{2}$, que constituem o colágeno, foi determinada por medida de densitometria após coloração do gel com Coomassie Blue.

As membranas de colágeno foram preparadas por secagem do gel em moldes retangulares de Teflon, à temperatura ambiente.

$\mathrm{O}$ espectro de absorção na região do infravermelho das membranas de colágeno foi obtido utilizando um espectrofotômetro BOMEN (FTIR). A razão das absorbâncias $1235 \mathrm{~cm}^{-1} / 1450 \mathrm{~cm}^{-1}$ foi determinada como medida da integridade da tripla hélice do colágeno ${ }^{14}$.

\section{Quitosana}

A quitosana (produto comercial da Fluka/Bio Chemica) foi purificada pela dissolução em solução aquosa de ácido acético $3 \%$ (v/v) por 24 h e filtração sob pressão positiva usando seqüencialmente filtros com porosidade de 5,0, 1,2 e $0,45 \mu \mathrm{m}$. A solução foi então 
neutralizada com $\mathrm{NH}_{4} \mathrm{OH}$ concentrado para a precipitação da quitosana. Posteriormente, filtrou-se o precipitado e seguiu-se lavagem com água destilada até a neutralidade. A quitosana foi então seca em estufa à $40^{\circ} \mathrm{C}$ por 1 semana.

Para a preparação das membranas, primeiro dissolveu-se a quitosana em solução de ácido acético $0,55 \mathrm{~mol} \mathrm{~L}^{-1}(\mathrm{pH} 3,5)$ e em seguida esta solução foi seca em moldes retangulares de Teflon, à temperatura ambiente.

Determinou-se o grau de acetilação (GA) da quitosana através do espectro de ressonância magnética nuclear de próton ${ }^{15}$, que foi obtido em um espectrômetro BRUKER AC de $200 \mathrm{MHz}$, utilizando uma amostra de quitosana com concentração de $10 \mathrm{mg} \mathrm{mL}^{-1} \mathrm{em}$ solução de água deuterada-ácido clorídrico 100:1 (v/v). A análise foi feita à $80^{\circ} \mathrm{C}$, utilizando o pulso de $90^{\circ}(8,2 \mu$ segundos $)$ e 16 varreduras de espectro acumulados.

O grau de acetilação foi determinado utilizando a seguinte expressão:

$\mathrm{GA} \%=\frac{\mathrm{A}_{\mathrm{CH} 3}}{3 \mathrm{~A}_{H 2}} \times 100$

onde,

$\mathrm{A}_{\mathrm{CH} 3}=$ área dos prótons metílicos do grupo acetamida

$\mathrm{A}_{\mathrm{H} 2}=$ área dos prótons ligados ao carbono $\mathrm{C}(2)$ do anel glicopiranosídico.

A massa molar da quitosana foi obtida pelo método viscosimétrico. Seis soluções de quitosana com concentrações que variaram de $6,0 \times 10^{-4}$ a $3,0 \times 10^{-4} \mathrm{~g} \mathrm{~mL}^{-1}$ foram preparadas usando tampão ácido acético $0,3 \mathrm{~mol} \mathrm{~L}^{-1} /$ acetato de sódio $0,2 \mathrm{~mol} \mathrm{~L}^{-1}, \mathrm{pH} \mathrm{4,5}$, como solvente. As viscosidades relativas foram medidas com viscosímetro capilar AVS-350. Os valores de tempo de escoamento empregados para a determinação da viscosidade reduzida correspondem à média de 4 determinações independentes. A massa molar (M) foi calculada pela relação de Mark-Houwink ${ }^{16,17}$ :

$[\eta]=K^{\prime} M^{a}$

onde, $[\eta]=$ viscosidade intrínseca, que foi obtida pela extrapolação à diluição infinita da curva de viscosidade reduzida versus concentração, e K' e a são constantes com valores ${ }^{18}$ de 0,0074 e 0,76 , respectivamente.

\section{Preparação das blendas}

Primeiramente diluiu-se a solução de colágeno para $0,7 \%(\mathrm{~m} / \mathrm{m})$ com solução de ácido acético $0,55 \mathrm{~mol} \mathrm{~L}^{-1}$ (pH 3,5). Logo após dissolveu-se a quitosana em solução de ácido acético $0,55 \mathrm{~mol} \mathrm{~L}^{-1}(\mathrm{pH} 3,5)$ até obter também uma solução $0,7 \%(\mathrm{~m} / \mathrm{m})$. A protonação da quitosana provoca um aumento do $\mathrm{pH}$, que foi corrigido com a adição de ácido acético até obter novamente $\mathrm{pH} 3,5$. As duas soluções foram misturadas estequiometricamente para obter blendas colágeno-quitosana nas proporções de 3:1, 1:1 e 1:3 (m/m) em pH 3,5. As blendas foram então agitadas por 5 min para homogeneização e colocadas para secar em moldes retangulares de Teflon, à temperatura ambiente.

\section{Caracterização das blendas}

\section{Espectroscopia de infravermelho}

Para obtenção dos espectros de absorção foram utilizadas as membranas das blendas. A razão das absorbâncias $1235 \mathrm{~cm}^{-1} / 1450 \mathrm{~cm}^{-1}$ também foi determinada para o colágeno nas blendas.

\section{Termogravimetria e calorimetria exploratória diferencial}

Para os estudos de estabilidade térmica foram utilizadas amostras de $10 \mathrm{mg}$ das membranas. As medidas foram feitas em equipamentos da TA Instruments DSC 2010 e TGA 2050 numa razão de aquecimento de $10{ }^{\circ} \mathrm{C} \mathrm{min}^{-1}$ em atmosfera de $\mathrm{N}_{2}$. O estudo termogravimétrico foi feito na faixa de 25 a $600{ }^{\circ} \mathrm{C}$ e a calorimetria exploratória diferencial na faixa de 25 a $200{ }^{\circ} \mathrm{C}$.

\section{Ensaios de viscosidade específica}

Para estes ensaios utilizou-se soluções de colágeno, quitosana e blendas com concentrações de $5 \mathrm{mg} \mathrm{mL}^{-1}$. As amostras foram ensaiadas em um viscosímetro capilar tipo Ostwald, número 300, com controlador de temperatura. Os valores de tempo de escoamento empregados para a determinação da viscosidade específica corresponderam à média de 3 determinações independentes.

\section{Absorção de água}

A quantidade de água absorvida pelas membranas foi determinada pela imersão em água destilada por um determinado período de tempo. Os tempos escolhidos foram $0,5,10$ e $20 \mathrm{~h}$.

Primeiramente, retirou-se toda a água das membranas em liofilizador até obter peso constante (aproximadamente $8 \mathrm{~h}$ ). Em seguida, as mesmas foram colocadas separadamente em frascos com água destilada e retiradas para pesagem após o período determinado. A pesagem das membranas foi feita retirando-se o excesso de água com papel de filtro.

A quantidade de água absorvida foi calculada pela equação:

$\%$ água $=\frac{\left(\mathrm{m}_{\mathrm{u}}-\mathrm{m}_{\mathrm{s}}\right)}{\mathrm{m}_{\mathrm{u}}} \times 100$

onde $m_{u}$ e $m_{s}$ são as massas das membranas úmida e seca, respectivamente. Os resultados representaram a média de três determinações independentes.

\section{Comportamento mecânico}

Para os ensaios mecânicos pelo módulo tração foram preparadas membranas em moldes retangulares de Teflon, de dimensões $10 \times 5 \mathrm{~cm}$. Destas membranas cortou-se tiras $10 \times 1 \mathrm{~cm}$, que foram mantidas em dessecador sob vácuo até o momento das medidas.

As medidas foram feitas à temperatura ambiente em uma máquina de testes SINTECH 6, utilizando uma cela de carga modelo 3397-136 com capacidade de $90 \mathrm{Kg}$. A distância inicial entre as garras foi de $30 \mathrm{~mm}$ e elas foram tracionadas a uma velocidade constante de $5 \mathrm{~mm} \mathrm{~min}^{-1}$.

\section{RESULTADOS E DISCUSSÃO}

Neste trabalho optou-se por preparar as blendas em pH 3,5, sendo que praticamente todos os grupos $-\mathrm{NH}_{3}{ }^{+}$da quitosana estão protonados e o colágeno está abaixo do seu ponto isoelétrico ( $\mathrm{pI} 7$ ), onde é mais acentuado o processo de fibrilogênese ${ }^{19}$, em que suas moléculas se organizam em forma de fibras, o que dificultaria a interação com as moléculas da quitosana.

\section{Caracterização do colágeno}

O perfil densitométrico obtido a partir do gel de colágeno (Figura 1) mostrou as bandas correspondentes às cadeias $\alpha_{1}$ e $\alpha_{2}$ numa 


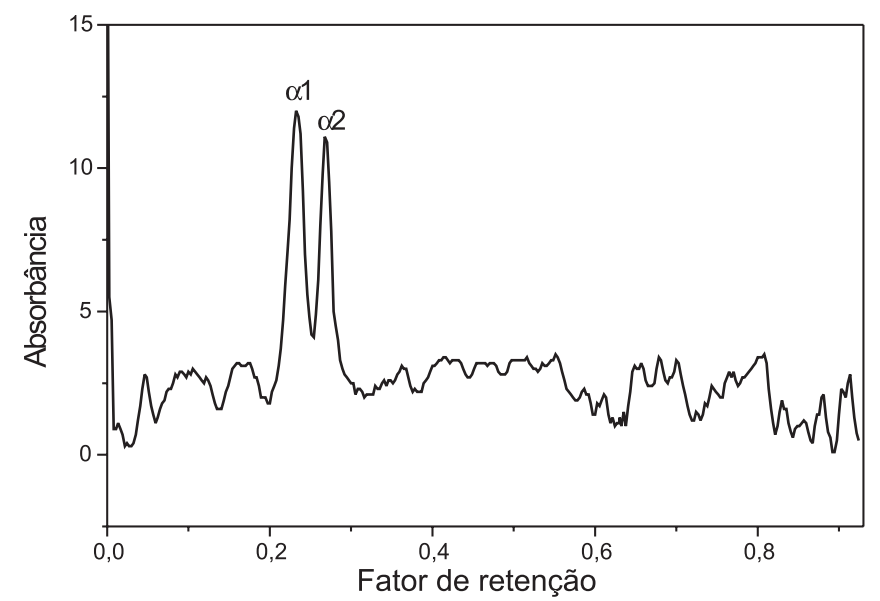

Figura 1. Perfil densitométrico do gel de colágeno

razão de 2:1, típica do colágeno do tipo $\mathrm{I}^{20}$. As massas molares calculadas a partir da curva de calibração dos padrões foram 112.000 Da para a cadeia $\alpha_{1}$ e 106.000 Da para a cadeia $\alpha_{2}$, valores estes que estão de acordo com os descritos na literatura para o colágeno do tipo $\mathrm{I}^{20}$.

\section{Caracterização da quitosana}

Pelo espectro de ${ }^{1} \mathrm{H}-\mathrm{RMN}$ da quitosana (Figura 2) obteve-se um grau de acetilação de aproximadamente $24 \%$. Este resultado pode ter uma variação de 5\%, que está relacionado com a escolha da linha de base e dos intervalos de integração para a obtenção do espectro.

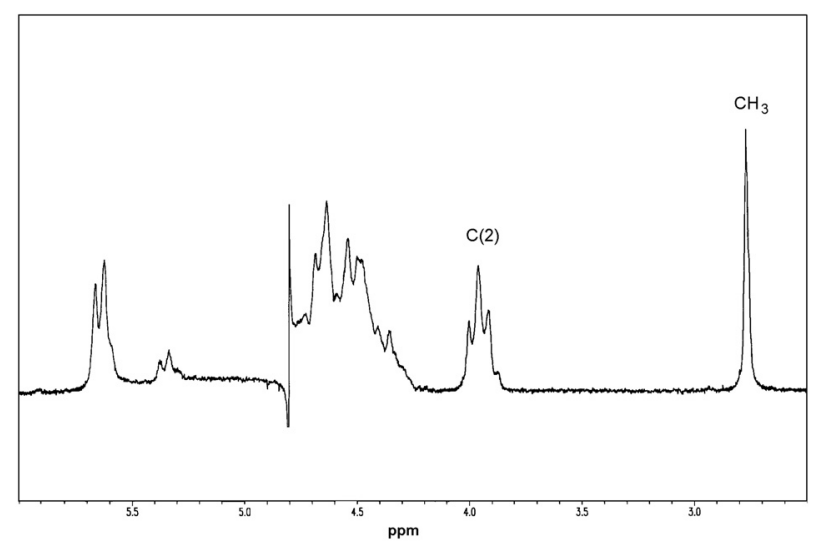

Figura 2. $\mathrm{H}^{1}$-RMN da quitosana em $\mathrm{HCl} / \mathrm{D}_{2} \mathrm{O}$

A massa molar determinada por ensaios de viscosidade foi de 140.000 Da. Este resultado não está de acordo com a massa molar dada pelo fabricante (400.000 Da), o que sugere que a amostra comercial não é homogênea e pode ter ocorrido fracionamento após o procedimento de purificação, ou o dado do fabricante é incorreto.

\section{Caracterização das blendas}

\section{Espectroscopia de infravermelho}

A Figura 3 mostra os espectros de infravermelho do colágeno, da quitosana e das blendas.

O espectro do colágeno (Figura 3a) apresenta as seguintes ban-

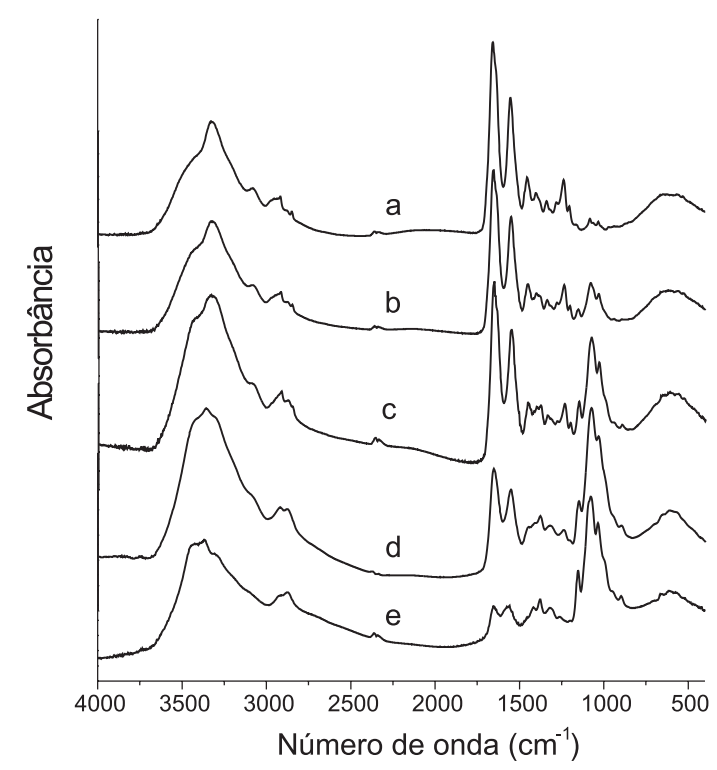

Figura 3. Espectros de infravermelho de: (a) colágeno, (b) colágenoquitosana 3:1, (c) colágeno-quitosana 1:1, (d) colágeno-quitosana 1:3 e (e) quitosana

das principais: em $1650 \mathrm{~cm}^{-1}$, típica de amida I, devido ao estiramento da carbonila, em $1560 \mathrm{~cm}^{-1}$, relacionado à amida II, devido as vibrações no plano da ligação N-H e ao estiramento C-N ${ }^{21}$, em $1235 \mathrm{~cm}^{-1}$, correspondente às vibrações no plano da amida III, devido ao estiramento $\mathrm{C}-\mathrm{N}$ e à deformação $\mathrm{N}-\mathrm{H}$, em $1450 \mathrm{~cm}^{-1}$, correspondente à estereoquímica dos anéis pirrolidínicos ${ }^{14}$ e próximo a $3450 \mathrm{~cm}^{-1}$, devido ao estiramento $\mathrm{O}-\mathrm{H}$. O espectro do colágeno também mostra a integridade da sua tripla hélice, através da relação das absorbâncias em 1235 e $1450 \mathrm{~cm}^{-1}$, devido à amida III e ligações $\mathrm{C}-\mathrm{H}$ do anel pirrolidínico ${ }^{14}$. Para materiais preparados em soluções ácidas ( $\mathrm{pH}$ 3,5), a integridade da estrutura secundária do colágeno pode ser verificada quando o valor da relação $1235 \mathrm{~cm}^{-1} / 1450 \mathrm{~cm}^{-1}$ for maior ou igual à unidade. Para o material utilizado neste trabalho, o valor encontrado para esta relação (Tabela 1) foi 0,98 , portanto, significativamente maior do que aquele que seria observado para estruturas desnaturadas, cujos valores estão por volta de $0,5^{14}$.

As bandas principais para o espectro da quitosana (Figura 3e) são: $1650 \mathrm{~cm}^{-1}$, correspondente a amida I, $1560 \mathrm{~cm}^{-1}$, relacionada a amida II, $1070 \mathrm{~cm}^{-1}$ e $1030 \mathrm{~cm}^{-1}$, devido ao estiramento C-O, próximo a $3450 \mathrm{~cm}^{-1}$, estiramento $\mathrm{O}-\mathrm{H}$, e $1314 \mathrm{~cm}^{-1}$ devido ao grupo CO-N-. A banda intensa entre 800 e $1200 \mathrm{~cm}^{-1}$ está relacionada com os anéis piranosídicos ${ }^{22}$.

Os espectros das blendas (Figuras 3b, c e d) são caracterizados pelas bandas do colágeno e da quitosana, sendo suas intensidades proporcionais à quantidade de cada material na blenda.

Para confirmar a ausência de novas bandas nos espectros das blendas, fez-se para todos a subtração pelo espectro da quitosana. Como

Tabela 1. Razão de absorbâncias $1235 \mathrm{~cm}^{-1} / 1450 \mathrm{~cm}^{-1}$ dos espectros de infravermelho do colágeno e das blendas

\begin{tabular}{cc}
\hline Proporção colágeno-quitosana & $\mathrm{A}_{1235} / \mathrm{A}_{1450}$ \\
\hline $1: 0$ & 0,98 \\
$3: 1$ & 0,99 \\
$1: 1$ & 0,99 \\
$1: 3$ & 0,97 \\
\hline
\end{tabular}


exemplificado na Figura 4, subtraindo-se o espectro da quitosana pelo da blenda 1:1, o resultante ficou idêntico ao espectro do colágeno. Com a ausência de novas bandas e a preservação da intensidade e forma daquelas já existentes, conclui-se que, se houver interações entre o colágeno e a quitosana, elas são puramente eletrostáticas, envolvendo os grupos $-\mathrm{NH}_{3}{ }^{+}$da quitosana e - $\mathrm{COO}^{-}$do colágeno. Este resultado já foi mencionado por outros autores na literatura, mas utilizando o atelocolágeno no lugar do colágeno nativo ${ }^{11}$.

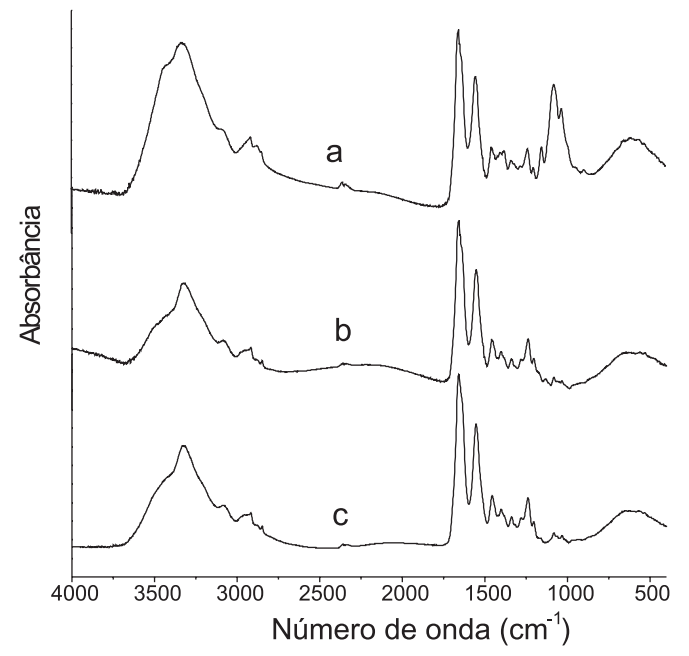

Figura 4. Espectros de IV: (a) blenda 1:1; (b) resultante da subtração do espectro da blenda 1:1 pelo espectro da quitosana e (c) colágeno

A integridade da estrutura em tripla hélice do colágeno também foi determinada para as blendas pela razão das absorbâncias $1235 \mathrm{~cm}^{-1} / 1450 \mathrm{~cm}^{-1}$, os resultados estão mostrados na Tabela 1. Esta razão para as blendas também foi próxima de 1, mostrando que a presença da quitosana não provoca desestabilização da tripla hélice do colágeno nas blendas.

\section{Termogravimetria}

As curvas termogravimétricas do colágeno, da quitosana e das blendas estão mostradas na Figura 5. Elas mostram uma perda de massa em dois estágios. O primeiro estágio (da temperatura ambiente até cerca de $200^{\circ} \mathrm{C}$ ) é atribuído à perda de água adsorvida e estrutural contida nos materiais, e o segundo estágio, iniciando-se próximo de $200{ }^{\circ} \mathrm{C}$ e indo até $500{ }^{\circ} \mathrm{C}$, é atribuído à degradação dos polímeros $^{23-25}$.

A Tabela 2 mostra a porcentagem de perda de massa dos materiais nos dois estágios e a quantidade de resíduo restante à $600{ }^{\circ} \mathrm{C}$. De acordo com a perda de massa do primeiro estágio, verifica-se que, aumentando a quantidade de quitosana nas blendas, maior é a quantidade de água perdida. No segundo estágio, nota-se que a degradação das blendas aumenta com o aumento da quantidade de colágeno. Isto também fica evidente na porcentagem de resíduo restante dos materiais a $600{ }^{\circ} \mathrm{C}$.

\section{Calorimetria exploratória diferencial}

As curvas de estabilidade térmica obtidas para o colágeno, quitosana e blendas estão mostradas na Figura 6. A curva do colágeno (Figura 6a) apresentou uma pequena transição em aproximadamente $54{ }^{\circ} \mathrm{C}$, correspondente a sua desnaturação. Para as blendas, a temperatura de desnaturação (Td) do colágeno ocorreu também próxima

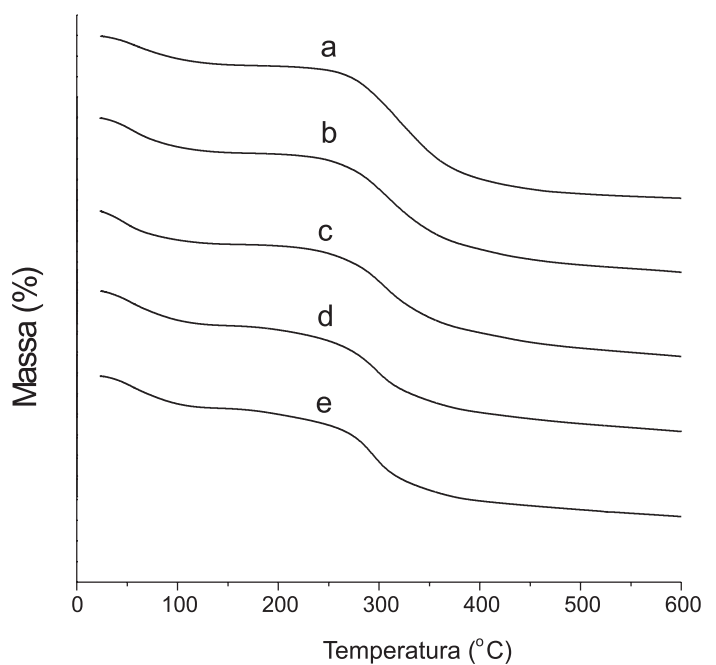

Figura 5. Curvas termogravimétricas das amostras de: (a) colágeno; (b) colágeno-quitosana 3:1; (c) colágeno-quitosana 1:1; (d) colágeno-quitosana 1:3; e (e) quitosana

Tabela 2. Perda de massa dos materiais nos estágios de 25 até $200{ }^{\circ} \mathrm{C}$ e de 200 até $500{ }^{\circ} \mathrm{C}$ e a quantidade de resíduo a $600{ }^{\circ} \mathrm{C}$

\begin{tabular}{cccc}
\hline & \multicolumn{3}{c}{ Perda de massa \% } \\
\cline { 2 - 4 } Proporção & $1^{\circ}$ estágio & $2^{\circ}$ estágio & Resíduo $(\%)$ \\
Colágeno-quitosana & $25-200^{\circ} \mathrm{C}$ & $200-500^{\circ} \mathrm{C}$ & à $600^{\circ} \mathrm{C}$ \\
\hline $\mathbf{1 : 0}$ & 14,5 & 61,8 & 21,2 \\
$\mathbf{3 : 1}$ & 17,4 & 53,7 & 24,9 \\
$\mathbf{1 : 1}$ & 16,7 & 49,5 & 29,2 \\
$\mathbf{1 : 3}$ & 18,7 & 45,5 & 31,6 \\
$\mathbf{0 : 1}$ & 18,5 & 46,2 & 31,8 \\
\hline
\end{tabular}

deste valor (Tabela 3), mostrando que a quitosana não alterou a estrutura nativa do colágeno em tripla hélice, como já mostrado anteriormente por espectroscopia no infravermelho.

A transição próxima à $115{ }^{\circ} \mathrm{C}$ está associada à perda de água ligada aos dois polímeros, e pelos valores de $\Delta \mathrm{H}$ (Tabela 3) pode-se notar que as blendas com maior quantidade de quitosana perdem mais água, confirmando o resultado da análise termogravimétrica.

Alguns autores mostraram a determinação da transição vítrea da quitosana e o estudo da miscibilidade de blendas de quitosana por calorimetria exploratória diferencial ${ }^{26}$. Neste trabalho não foi possível fazer o mesmo estudo, pois existe a necessidade de se fazer um préaquecimento das blendas, o que acabaria por desnaturar o colágeno.

\section{Ensaios de viscosidade específica}

A Figura 7 mostra o comportamento da viscosidade específica das soluções de colágeno, quitosana e blendas a pH 3,5, em função da temperatura. A solução de colágeno apresenta viscosidade aproximadamente três vezes maior do que a solução de quitosana com a mesma concentração. As viscosidades das blendas são intermediárias às viscosidades do colágeno e da quitosana.

Para as soluções de colágeno e das blendas no intervalo de $25^{\circ} \mathrm{C}$ a $35{ }^{\circ} \mathrm{C}$ as viscosidades decresceram, mantendo uma pequena diferença entre seus valores. À partir de $35^{\circ} \mathrm{C}$ as viscosidades destas soluções passaram a decrescer rapidamente, devido à desnaturação 


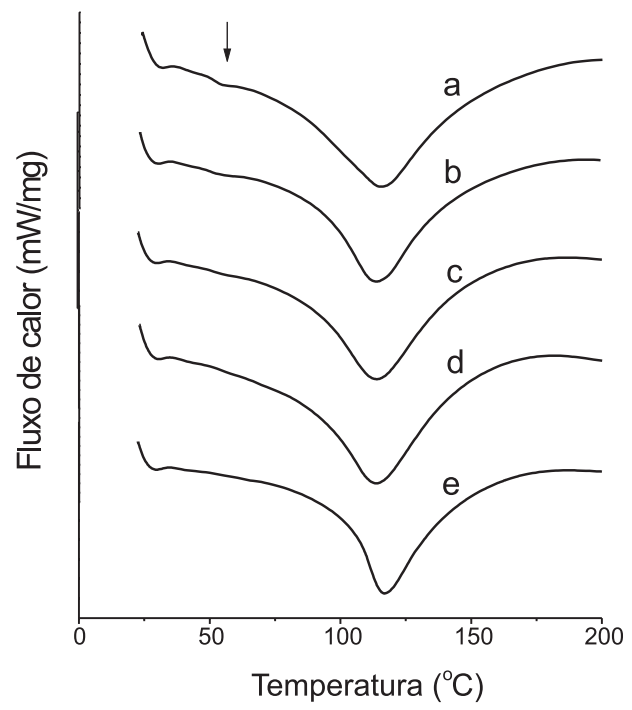

Figura 6. Curvas de estabilidade térmica das amostras de: (a) colágeno; (b) colágeno-quitosana $3: 1$; (c) colágeno-quitosana $1: 1$; (d) colágenoquitosana 1:3 e (e) quitosana

Tabela 3. Transições térmicas obtidas por DSC para as membranas de colágeno, quitosana e blendas

\begin{tabular}{cccc}
\hline \multirow{2}{*}{$\begin{array}{c}\text { Proporção } \\
\text { colágeno-quitosana }\end{array}$} & \multicolumn{3}{c}{ Transição térmica $\left({ }^{\circ} \mathrm{C}\right)$} \\
\cline { 2 - 4 } & 1 & 2 & $\Delta \mathrm{H}\left(\mathrm{J} \mathrm{g}^{-1}\right)$ \\
\hline $1: 0$ & 54,2 & 114,8 & 317,4 \\
$3: 1$ & 54,2 & 114,3 & 352,8 \\
$1: 1$ & 54,5 & 114,1 & 361,6 \\
$1: 3$ & $*$ & 113,8 & 386,7 \\
$0: 1$ & - & 116,9 & 393,1 \\
\hline
\end{tabular}

*não foi possível obter esta transição, devido à baixa concentração do colágeno na blenda

do colágeno. Já a solução de quitosana teve uma diminuição gradual da viscosidade na faixa de temperatura estudada.

A temperatura de desnaturação do colágeno pode ser obtida pelo ponto de inflexão das curvas (Tabela 4). A temperatura de desnaturação do colágeno nas blendas foi próxima de $42,5^{\circ} \mathrm{C}$, o que confirma que a quitosana não altera a estrutura de tripla hélice do colágeno em solução, como também indicado por DSC e espectroscopia no infravermelho para os materiais na forma de membrana, embora nesta forma, a temperatura de desnaturação tenha sido próxima de $54{ }^{\circ} \mathrm{C}$. Isto se deve ao fato de que, em solução, as moléculas apresentam maior mobilidade e, portanto, maior facilidade das ligações serem rompidas quando submetidas a variações de temperatura.

\section{Absorção de água}

A Figura 8 compara a capacidade de absorção de água das membranas das blendas com as membranas de colágeno e quitosana. Notase pelas curvas que todas as membranas atingiram a máxima quantidade de água após meia hora de imersão e a quantidade de água absorvida pelas membranas aumenta proporcionalmente com o aumento da quantidade de quitosana na blenda, o que está relacionado com a maior hidrofilicidade da quitosana $(\mathrm{GA}=24 \%)$, comparado

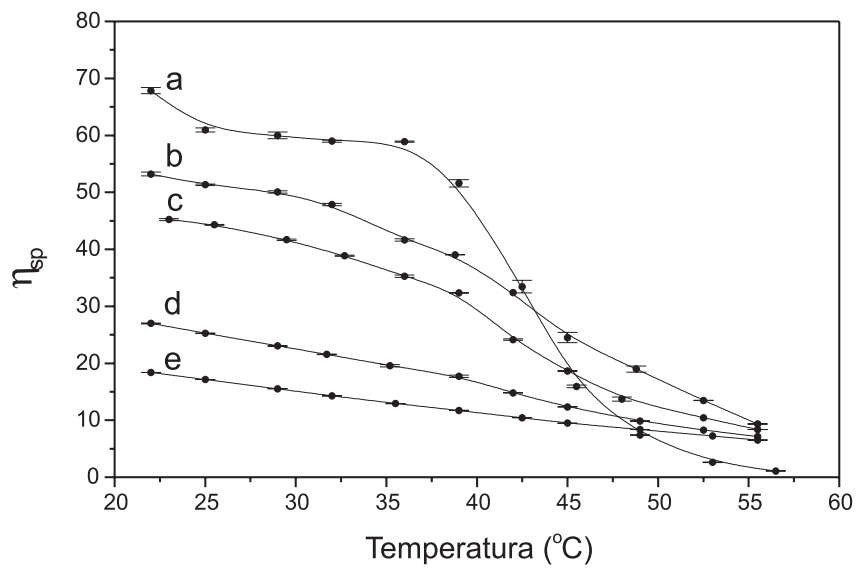

Figura 7: Efeito da temperatura sobre a viscosidade específica de soluções de: (a) colágeno; (b) colágeno-quitosana 3:1; (c) colágeno-quitosana 1:1; (d) colágeno-quitosana 1:3 e (e) quitosana

Tabela 4: Temperatura de desnaturação do colágeno obtida pelo ponto de inflexão das curvas de viscosidade específica

\begin{tabular}{cc}
$\begin{array}{c}\text { Proporção } \\
\text { colágeno-quitosana }\end{array}$ & $\begin{array}{c}\text { Temperatura de desnaturação do } \\
\text { colágeno (ponto de inflexão da curva) }\end{array}$ \\
\hline $1: 0$ & 42,5 \\
$3: 1$ & 42,6 \\
$1: 1$ & 42,3 \\
$1: 3$ & 42,2 \\
\hline
\end{tabular}

com o colágeno. Assim, é possível controlar o entumescimento das membranas, entre aproximadamente $70 \%$ e $80 \%$, variando-se a proporção de cada um dos polímeros na blenda. Este resultado é importante para a utilização destas membranas como implantes, matrizes para liberação controlada de drogas e membranas permeáveis.

Estes resultados estão de acordo com as análises térmicas, as quais mostraram que, quanto maior a quantidade de quitosana na blenda, maior a quantidade de água retida pelas membranas.

\section{Comportamento mecânico}

As curvas representativas de tensão-deformação das amostras de colágeno, quitosana e blendas, através de ensaios de tração mecânica, estão mostradas na Figura 9. As curvas exibem comportamentos semelhantes e podem ser classificadas em três regiões: 1) a região inicial é linear e corresponde a fase elástica; 2) a região curva, consecutiva à linear, corresponde à deformação plástica uniforme, sendo que o material não sofre estrangulamento e 3) região plástica não uniforme, marcada pelo estrangulamento da amostra. Nesta região a deformação também varia linearmente com a tensão.

Apesar das curvas da Figura 9 apresentarem um aspecto semelhante, nota-se que o colágeno e a quitosana tem comportamentos opostos nas regiões elástica e plástica. Na região elástica o colágeno deforma mais que a quitosana, embora esta última suporte maior tensão no limite de elasticidade. Já na região plástica este comportamento é invertido, ou seja, a quitosana passa a deformar mais que o colágeno para um mesmo valor de tensão, enquanto o colágeno é capaz de suportar maiores tensões que a quitosana. Estes comportamentos obtidos para o colágeno e a quitosana são repassados para as blendas de acordo com as suas proporções. Assim, as blendas com maior quantidade de colágeno devem suportar maiores tensões antes 


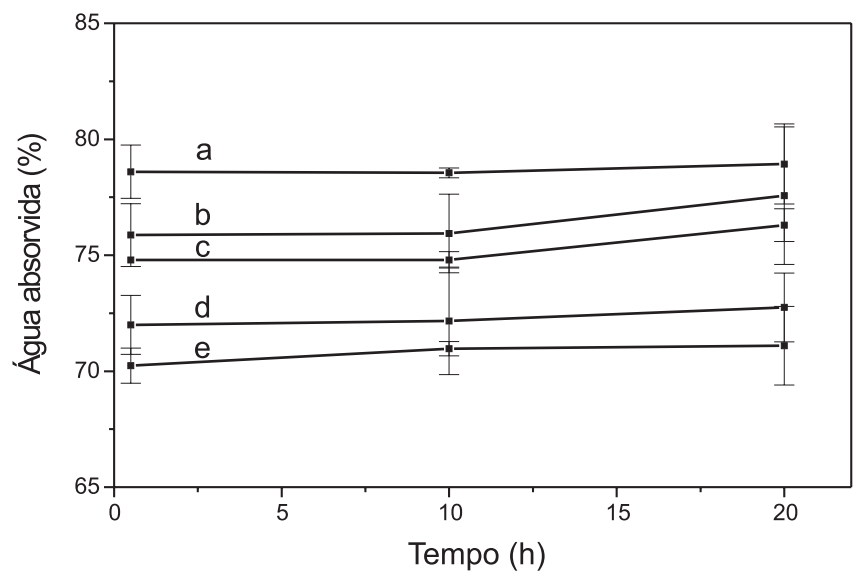

Figura 8. Porcentagem de água absorvida pelas membranas de: (a) colágeno; (b) colágeno-quitosana $3: 1$; (c) colágeno-quitosana $1: 1$; (d) colágeno-quitosana 1:3 e (e) quitosana

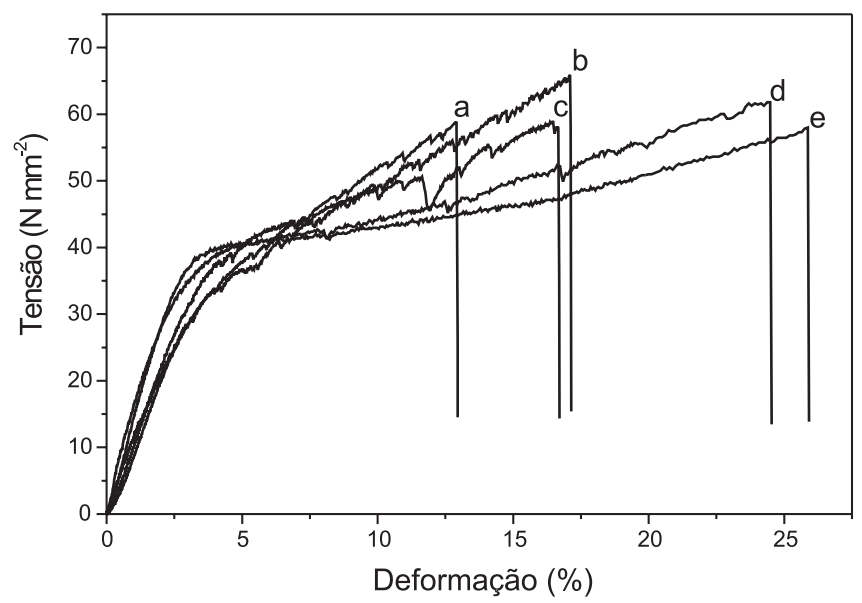

Figura 9. Curvas representativas de tensão-deformação para: (a) colágeno; (b) colágeno-quitosana 3:1; (c) colágeno-:quitosana 1:1; (d) colágenoquitosana 1:3 e (e) quitosana

da ruptura, enquanto as blendas com maior quantidade de quitosana devem deformar mais.

Não foi possível determinar a tensão, nem a deformação no momento da ruptura dos materiais, devido à presença de pequenas fibras de colágeno nos corpos de prova, impedindo a reprodutibilidade dos ensaios.

O comportamento intermediário das blendas em relação aos seus constituintes pode ser notado também pelos valores de módulo de Young e tensão de escoamento dos cinco materiais (Tabela 5).

\section{CONCLUSÕES}

Neste trabalho foi mostrado um método simples e rápido de preparação de géis e membranas de blendas colágeno-quitosana em diferentes proporções. Foram estudadas por espectroscopia de infravermelho, calorimetria exploratória diferencial e ensaios de viscosidade específica as possíveis interações entre estes dois polímeros e foi mostrado que a quitosana não interfere no arranjo estrutural do colágeno em tripla hélice, tanto em solução como na forma de membranas. Este é um resultado importante, pois a estrutura do colágeno
Tabela 5. Propriedades mecânicas pelo módulo de tração das amostras de colágeno, quitosana e blendas

\begin{tabular}{ccc}
\hline $\begin{array}{c}\text { Proporção } \\
\text { colágeno-quitosana }\end{array}$ & $\begin{array}{c}\text { Módulo de Young } \\
\left(\mathrm{N} \mathrm{mm}^{-2}\right)\end{array}$ & $\begin{array}{c}\text { Tensão no escoamento } \\
\left(\mathrm{N} \mathrm{mm}^{-2}\right)\end{array}$ \\
\hline $1: 0$ & $39 \pm 3$ & $22 \pm 2$ \\
$3: 1$ & $41 \pm 3$ & $24 \pm 2$ \\
$1: 1$ & $44 \pm 3$ & $27 \pm 2$ \\
$1: 3$ & $46 \pm 3$ & $30 \pm 2$ \\
$0: 1$ & $50 \pm 3$ & $32 \pm 2$ \\
\hline
\end{tabular}

em tripla hélice é responsável em grande parte por suas propriedades mecânicas e biológicas.

As propriedades das blendas como capacidade de absorção de água, estabilidade térmica e resistência à tração e deformação são intermediárias àquelas apresentadas pelos materiais individuais e podem ser controladas variando-se a proporção do colágeno e da quitosana.

As blendas obtidas neste trabalho poderão ser utilizadas como biomateriais nas formas de gel e membrana em variadas aplicações, como veículo de liberação de drogas, bandagens, géis injetáveis, membranas periodontais, etc.

\section{AGRADECIMENTOS}

Aos técnicos E. Biazin, G. D. Broch e V. C. A. Martins pela colaboração e à Capes pela bolsa e o suporte financeiro.

\section{REFERÊNCIAS}

1. Vidik, A.; Vuust, J.; Biology of Collagen, Academic Press: New York, 1980.

2. Chamberlain, L. J.; Yannas, I.V.; Arrizabalaga, A.; Hsu, H. P.; Norregard, T. V.; Spector, M.; Biomaterials 1998, 19,1393.

3. Yao, K.; Peng, T.; Yin, Y.; Xu, M. X.; Macromol. Chem. Phys. 1995, C35, 158

4. Muzzarelli, R. A. A.; Mattioli-Belmonte, M.; Tietz, C.; Biagini, R.; Ferioli, G.; Brunelli, M. A.; Fini, M.; Giardino, R.; Ilari, P.; Biagini, G.; Biomaterials 1994, 15, 1075.

5. Miyata, T.; Taira, T.; Noishiki, Y.; Clin. Mater. 1992, 9, 139.

6. Biagini, G.; Bertani, A.; Muzzarelli, R.; Damatei, A.; Dibenedetto, G.; Belligolli, A.; RicotiI, G.; Biomaterials 1991, 12, 281

7. Thomas, D. A.; Sperling, L. H. Em Polymer Blends; Paul, D. R.; Newman, S., eds.; Academic Press: New York, 1978, p. 3.

8. Utracki, L. A.; Polymer Alloys and Blends: Thermodynamics and Rheology, Hanser Publishers: New York, 1990, p. 1-27.

9. Thacharodi, D.; Rao, P. K.; Int. J. Pharm. 1995, 120, 115.

10. Izume, M.; Tairat, T.; Kimura, J.; Miyata, T. Em $4^{\text {th }}$ International Conference on Chitin and Chitosan, Elsevier: London, p. 653.

11. Taravel, M. N.; Domard, A.; Biomaterials 1993, 14, 930.

12. Goissis, G.; Plepis, A. M. G.; Rocha, J. L.; Br PI 9.405.043-0 A, 1996.

13. Laemmli, U. K.; Nature 1970, 227, 680.

14. George, A.; Veis, A.; Biochemistry 1991, 30, 2372.

15. Hirai, A.; Odani, H.; Nakajima, A.; Polym. Bull. 1991, $26,87$.

16. Yomota, C.; Miyazaki, T.; Okada, S.; Colloid. Polym. Sci. 1993, 271, 76

17. Wang, W.; Bo, S.; Li, S.; Qin, W.; Int. J. Biol. Macromol. 1991, 13, 281.

18. Rinaudo, M.; Milas, D. P. L.; Int. J. Biol. Macromol. 1993, 15, 281.

19. Veis, A.; Conn. Tiss. Res. 1982, 10, 11.

20. Ramachandran, G. N.; Treatise on Collagen, Academic Press: London, 1967, p. 103

21. Payne, K. J.; Veis, A.; Biopolymers 1988, 27, 1749.

22. Shigemasa, Y.; Matsuura, H.; Sashiwa, H.; Saimoto, H.; Int. J. Biol. Macromol. 1996, 18, 237.

23. Privalov, P. I.; Tiktopulo, E. I.; Biopolymers 1970, 9, 127.

24. Cárdenas, T. G.; Ernal, A. L.; Tagle, D. L. H.; Thermochim. Acta 1992, $195,33$.

25. Nieto, J. M.; Peniche, A. C. C.; Thermochim. Acta 1991, 176, 63.

26. Sakurai, K.; Maegawa, T.; Takahashi, T.; Polymer 2000, 41, 7051 . 